\title{
Eustachian tube function in patients with chronic tubotympanic suppurative otitis media with Eustachian tube dysfunction after tympanoplasty
}

\author{
Borysenko O. Grynko I. \\ State institution «O. S. Kolomiychenko Institute of Otolaryngology of \\ National Academy of Medical Sciences of Ukraine» \\ e-mail: amtc@kndio.kiev.ua
}

\begin{abstract}
Actuality: In the treatment of chronic tubotympanic suppurative otitis media, one of the main conditions for a successful treatment is a sufficient function of the Eustachian tube (ET). Earlier, the 5th stage of ET function was considered as a contraindication for tympanoplasty. The inflation-deflation test allows accurately assess the degree of dysfunction of the ET and optimize surgical tactics.

Aim of the study: To determine the dynamic changes in ET function in patients with chronic tubotympanic suppurative otitis media with dysfunction of ET after tympanoplasty according to the inflationdeflation test.

Materials and Methods: We examined 105 patients aged 19 to 56 years, 57 were women and 48 men. At the 1 st -4 th grade of ET function according to inflation-deflation test, the result was interpreted as normal - patients underwent tympanoplasty without ventilation tubes (VT). At the 5th stage of ET function, the result was interpreted as abnormal (dysfunction of the ET) - patients underwent tympanoplasty with teflon or silicone VT. Inflation-deflation test was performed in all patients postoperatively after 3, 6, 12 months. With the improvement of ET function (changing grade from 5th to 1-4th, the VT was removed).

Results and discussion: Was found that in men, the 5th grade of ET dysfunction is observed less often (37.5\%) than in women $(52.6 \%)$. Improvement of ET function in patients with teflon VT is faster than in patients with silicone VT. At the same time, restoration of the tympanic membrane leads to decrease of the 5th grade of the ET function when comparing between the 3rd and 6th and 12th months, and also between the 6th and 12th months after surgery in both groups of men and women.

Conclusions: Tympanoplasty in patients with chronic tubotympanic suppurative otitis media improves the ET function. The inflationdeflation test is an objective method and should be the basic examining the ET in the candidate for tympanoplasty.
\end{abstract}

Key words: chronic tubotympanic suppurative otitis media, inflation - deflation test, Eustachian tube, tympanoplasty, ventilation tube.

\section{Actuality}

Chronic tubotympanic suppurative otitis media caused by acute inflammation of the middle ear or rupture of the tympanic membrane due to injuries which, in addition to living conditions, can be caused by an explosive wave.

Inflammatory process in the middle ear exist due to many factors, most significant are bacterial flora and Eustachian tube (ET) dysfunction. The achievement in treating patient with ET dysfunction is long ventilation and drainage of the tympanic cavity, as a result function of the ET could improve. Tympanic membrane perforation leads permanent irritation of the tympanic cavity and ET with cold or hot air, contact of mucosa with dust, water, and the content of the external auditory canal. Closing tympanic membrane perforation is one of the main conditions for mucosa of the middle ear and ET recovery.

\section{Aim of the study}

The aim of the study was to evaluate the dynamics of ET function restoration in patients with chronic tubotympanic suppurative otitis media with ET dysfunction after tympanoplasty with ventilation $\mathrm{T}$ - tubes according to the inflation - deflation test. 


\section{Materials and Methods}

We examined 105 patients before tympanoplasty in the department of ear microsurgery and otoneurosurgery in state O.S. Kolomiychenko Institute of Otolaryngology in Kiev. Among the patients, there were 57 females and 48 male aged 19 to 56 years. Among male, 13 patients were military men, at their case perforation of tympanic membrane appeared as a result of explosion. The study included patients who had no diagnosed pathology of the nose, sinuses and nasopharynx during the examination.
In order to evaluate ventilation function of ET we used analyzer of the middle ear Interacoustics AT235h in ETF2 mode. Inflation-deflation test was performed.

The inflation-deflation test starts from the patient instruction about swallowing during the study. In ETF2 mode, the pressure in the external auditory canal was increased to $+300 \mathrm{daPa}$, then the pressure was reduced to-350 daPa. During swallowing, middle ear pressure change was fixed.

The results of the inflation-deflation test were estimated on the Miller G.F. scale, which includes 5 grades of ET function (Fig. 1)

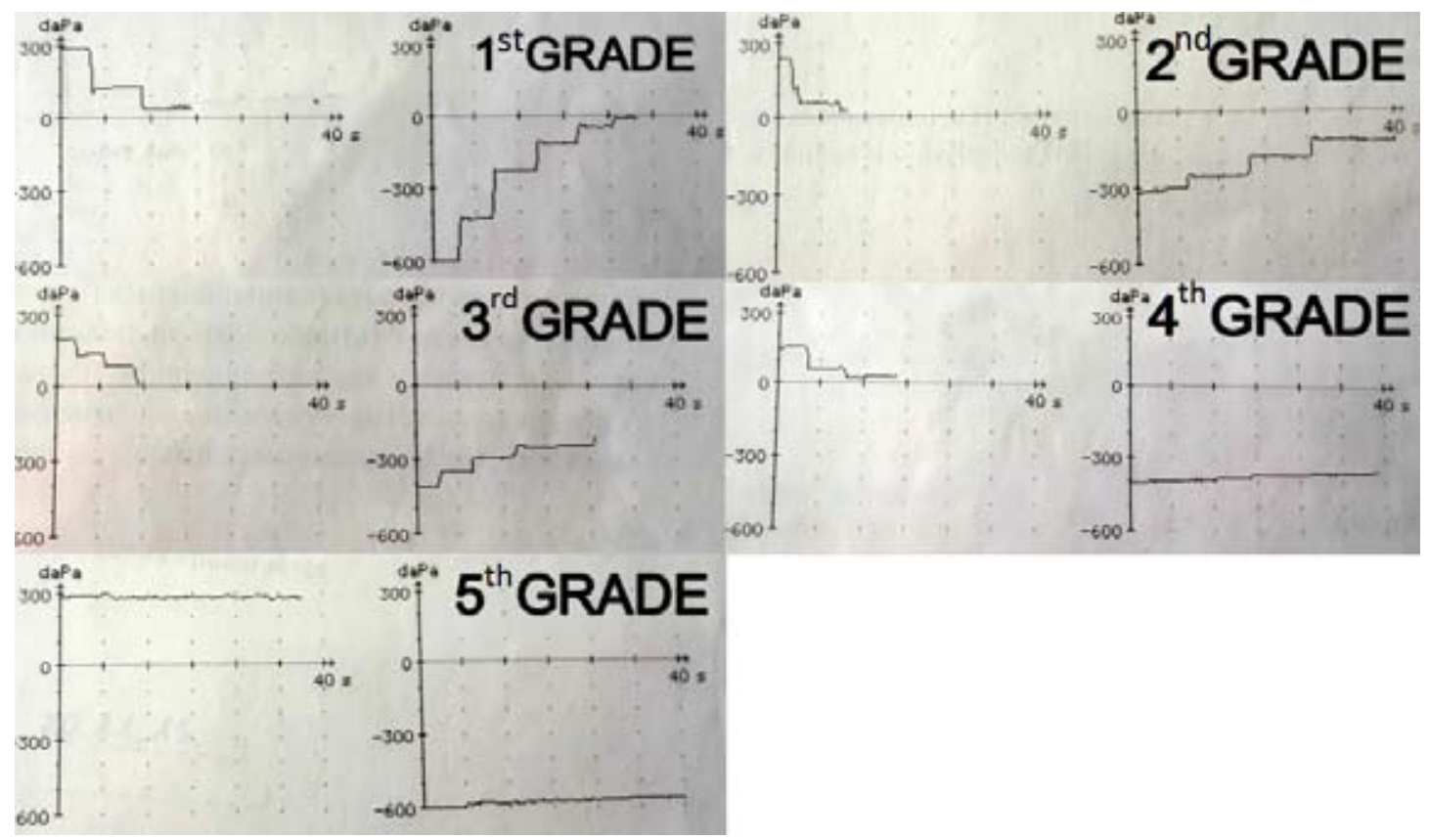

Fig. 1. G.F. Miller scale of ET function.

1st grade - Positive and negative pressure in the middle ear cavity is equal to 0 after patients swallowing.

2nd grade - Positive pressure is equal to 0 . Negative pressure remains within $-50 \mathrm{daPa}$.

3rd grade. - Positive pressure is equal to 0 . Negative pressure remains below $-100 \mathrm{daPa}$.

4 th grade - the positive pressure is equal to 0 . Negative pressure remains between $100-250 \mathrm{daPa}$.

5rd grade - ET tube does not open at positive or negative pressure.

1-3 grade was considered as a good function; $4^{\text {th }}$ grade as medium dysfunction; $5^{\text {th }}$ grade as evident ET dysfunction.

Tympanoplasty was performed in all cases with temporal fascia. „Underlay“ technique was used. In patients with 1st-4th grade of the ET function, the result was considered as acceptable - tympanoplasty was performed without ventilation T-tubes (VT). In patients with 5th grade of ET function, result was considered as ET dysfunction - tympanoplasty was performed with teflon or silicon VT.

To place VT under tympanic membrane, channel was formed with electric bur in which VT was inserted. One part was opened in tympanic cavity under the annulus and temporal fascia and the other part was open in external ear canal. Method was described by Herbert Silverstein in 1976 (Fig. 2) 

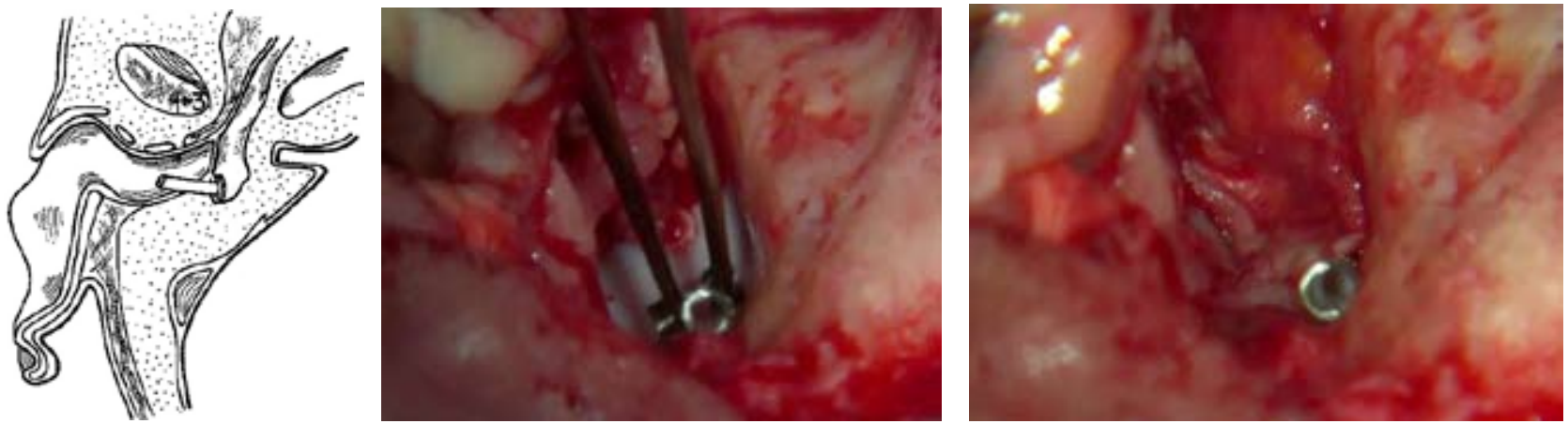

Fig. 2. Tympanoplasty method described by Herbert Silverstein.

After the tympanoplasty, the external ear canal was packed with merocel wick for 1 month. In a month dressing were removed. In 3,6,12 months' inflationdeflation test was performed. In case of ET function improvement (transfer from 5 th to $1^{\text {st }}-4$ th grade of ET function), the VT was removed. Tympanometry was used for future control.

\section{Results}

According to our data, 5th grade of ET function in male was noted in $37.5 \%$, and the $1 \mathrm{st}$ - 4th grade in $62.5 \%$ of cases. In female, the 5 th grade of ET function was noted in $52.6 \%$, and the 1st - 4th grade in $47.4 \%$ of cases. Among military patients in $100 \%$ of cases $1^{\text {st }}$ grade of ET function was detected.

Tab. 1. Inflation - deflation test results in male and female before the operation (\%).

\begin{tabular}{|c|c|c|c|c|c|c|c|}
\hline \multirow[b]{2}{*}{ ET grade } & \multicolumn{4}{|c|}{ Male $(n=48)$} & \multicolumn{3}{|c|}{ Female $(n=57)$} \\
\hline & $\begin{array}{c}\text { T/WO } \\
(n=16)\end{array}$ & $\begin{array}{c}\text { T/TVT } \\
(\mathrm{n}=12)\end{array}$ & $\begin{array}{l}\text { T/SVT } \\
(n=7)\end{array}$ & $\begin{array}{c}\text { MILIT } \\
(n=13)\end{array}$ & $\begin{array}{c}\text { T/WO } \\
(n=27)\end{array}$ & $\begin{array}{c}\text { T/TVT } \\
(n=17)\end{array}$ & $\begin{array}{c}\text { T/SVT } \\
(\mathrm{n}=13)\end{array}$ \\
\hline 1 & 50,0 & 0 & 0 & 100 & 40,7 & 0 & 0 \\
\hline 2 & 12,5 & 0 & 0 & 0 & 29,6 & 0 & 7,7 \\
\hline 3 & 25,0 & 0 & 0 & 0 & 18,5 & 0 & 0 \\
\hline 4 & 12,5 & 0 & 14,3 & 0 & 7,4 & 0 & 0 \\
\hline 5 & 0 & 100 & 85,7 & 0 & 3,7 & 100 & 92,3 \\
\hline
\end{tabular}

1. T/WO - tympanoplasty without ventilation T-tube;

2. T/TVT - tympanoplasty with teflon ventilation T-tube

3. T/SVT - tympanoplasty with silicone ventilation T-tube;

4. MILIT - military patients, tympanoplasty without VT.

Dynamical change of the ET function after surgery in male with T/TVT shows decreasing number of 5th grade of ET function to $75.0 \%$ in 3 months, to $25.0 \%$ in 6 months and was absent in 12 months after surgery. In male with T/SVT, the 5 th grade of
ET function registered in $85.7 \%$ of cases before surgery, decreases to $57.1 \%$ in 3 months, to $28.6 \%$ in 6 months and to $14.3 \%$ in 12 months after tympanoplasty. 
Tab. 2. Dynamic change of the ET function after tympanoplasty with teflon and silicon VT in male and female (\%).

\begin{tabular}{|c|c|c|c|c|c|c|c|c|}
\hline \multirow{2}{*}{ ET grade } & \multicolumn{4}{|c|}{ Male T/TVT $(n=12)$} & \multicolumn{4}{|c|}{ Female T/TVT $(n=17)$} \\
\hline & Pre Oper. & 3 months. & 6 months. & $\begin{array}{c}12 \\
\text { months. }\end{array}$ & Pre Oper. & $\begin{array}{c}3 \\
\text { months. }\end{array}$ & $\begin{array}{c}6 \\
\text { months. }\end{array}$ & $\begin{array}{c}12 \\
\text { months. }\end{array}$ \\
\hline 1 & 0 & 0 & 0 & 0 & 0 & 5,9 & 11,8 & 0 \\
\hline 2 & 0 & 8,3 & 8,3 & 0 & 0 & 11,8 & 11,8 & 0 \\
\hline 3 & 0 & 16,7 & 25,0 & 8,3 & 0 & 17,6 & 23,5 & 5,9 \\
\hline 4 & 0 & 0 & 8,3 & 8,3 & 0 & 11,8 & 0 & 5,9 \\
\hline 5 & 100 & 75,0 & 25,0 & 0 & 100 & 52,9 & 11,8 & 0 \\
\hline \multirow{2}{*}{ ET grade } & \multicolumn{4}{|c|}{ Male T/SVT $(n=7)$} & \multicolumn{4}{|c|}{ Female T/SVT $(n=13)$} \\
\hline & Pre Oper. & 3 months. & 6 months. & $\begin{array}{c}12 \\
\text { months. }\end{array}$ & Pre Oper. & $\begin{array}{c}3 \\
\text { months. }\end{array}$ & $\begin{array}{c}6 \\
\text { months. }\end{array}$ & $\begin{array}{c}12 \\
\text { months. }\end{array}$ \\
\hline 1 & 0 & 0 & 0 & 0 & 0 & 7,7 & 0 & 7,7 \\
\hline 2 & 0 & 14,3 & 0 & 0 & 7,7 & 0 & 7,7 & 0 \\
\hline 3 & 0 & 14,3 & 14,3 & 14,3 & 0 & 23,1 & 7,7 & 7,7 \\
\hline 4 & 14,3 & 14,3 & 28,6 & 0 & 0 & 0 & 15,4 & 7,7 \\
\hline 5 & 85,7 & 57,1 & 28,6 & 14,3 & 92,3 & 69,2 & 23,1 & 7,7 \\
\hline
\end{tabular}

In female T/TVT, the 5th grade of ET function registered in $100 \%$ of cases before surgery, decreases to $52.9 \%$ in 3 months, to $11.8 \%$ in 6 months and was absent in 12 months after surgery. In female T/SVT, the 5th grade of ET function diagnosed in $92.3 \%$ of cases, decreases to $69.2 \%$ in 3 months, to $23.1 \%$ in 6 months and to $7.7 \%$ in 12 months after surgery.

It should be noted that percentage of the 5th grade of ET function decrease in all groups when comparing data in 3rd, 6th and 12th months, as well as between data in 6 th and 12 th months after surgery (Tab. 2).

In all cases we had good morphological results. In some cases, we observe partial neotympanic membrane epidermisation in 3 month. In 6 month complete neotympanic membrane epidermisation was observed in all cases.

\section{Discussion}

To evaluate the ET function in most physiological way, artificial creation of positive and negative pressure in external ear canal and tympanic cavity is required. The new generation of impedance audiometers allows to quantify and register ET function in positive and negative pressure. The advantage of this method is in measuring pressure changes not in the nasopharynx, but in the external ear canal and the tympanic cavity, which is more physiological. At the same time, in patients with chronic tubotympanic suppurative otitis media, one of the main conditions for the restoration of ET function is the closed tympanic cavity. Perforated tympanic membrane doesn't isolate the tympanic cavity from cold or hot air, dust, moisture, water. According to this, one of the main conditions for restoration of the ET function in chronic otitis media is restoration of the tympanic membrane with the simultaneous ventilation of the tympanic cavity with VT bypassing the ET.

In patients with $5^{\text {th }}$ grade of ET function, in which timpanoplasty was performed with VT, the inflation-deflation test allows to evaluate the dynamic change of ET function after tympanoplasty.

In the study of ET function according to our data, it was found that in male the 5th grade of ET function was observed less frequently $(37.5 \%)$ than in female $(52.6 \%)$. Among military patients with traumatic perforation of tympanic membrane, in all cases $1^{\text {st }}$ grade of ET function was found, which may indicate the absence of inflammatory process in the tympanic cavity and ET.

Studying dynamic changes of ventilation function of ET in male, it is necessary to note the improvement of ET function of both using teflon and silicon VT. Using teflon VT, the 5th grade of ET function in 3 months was registered in $75.0 \%$ cases, after 6 months in $25.0 \%$, and was absent in 12 months. Using teflon VT in female, the 5th degree of ET function in 3 months was registered in $52.9 \%$ cases, in 6 months at $11.8 \%$, and was absent in 12 months afrer surgery (Fig. 3). 



Fig. 3. Male and female 5th grade dynamic change.

According to our data, the improvement of ET function in patients with teflon VT is faster than in patients with silicone VT.

$5^{\text {th }}$ grade of ET function, registered in $45.7 \%$ cases of chronic tubotympanic suppurative otitis media preoperatively. Probably the number of patients with ET dysfunction may be higher than it is considered. Inaccuracy in ET function evaluation before tympanoplasty can be the reason of recurrent perforation. Inflation-deflation test should play an important role in patients - candidates for tympanoplasty.

\section{Clinical case}

Female, 36 y.o. applied for a consultation with complaints of hearing loss on the right ear, a peri- odical otorrhea. During otomicroscopy a subtotal perforation of pars tensa was identified. Mucosa of middle ear was pink. The Valsalva maneuver was positive. At endoscopic examination of the nasopharynx by the endoscope $4 \mathrm{~mm} 0^{\circ}$ - no pathology of nasal septum, lower nasal turbinate, the nasopharynx without signs of inflammation, cartilaginous part of ET without pathology, no discharge during swallowing. In the audiometry $35 \mathrm{~dB}$ of air bone gap. Inflation-deflation test registered $5^{\text {th }}$ grade of ET function. Tympanoplasty with teflon VT was planned. Temporal muscle fascia was used for perforation closure (Fig. 4).
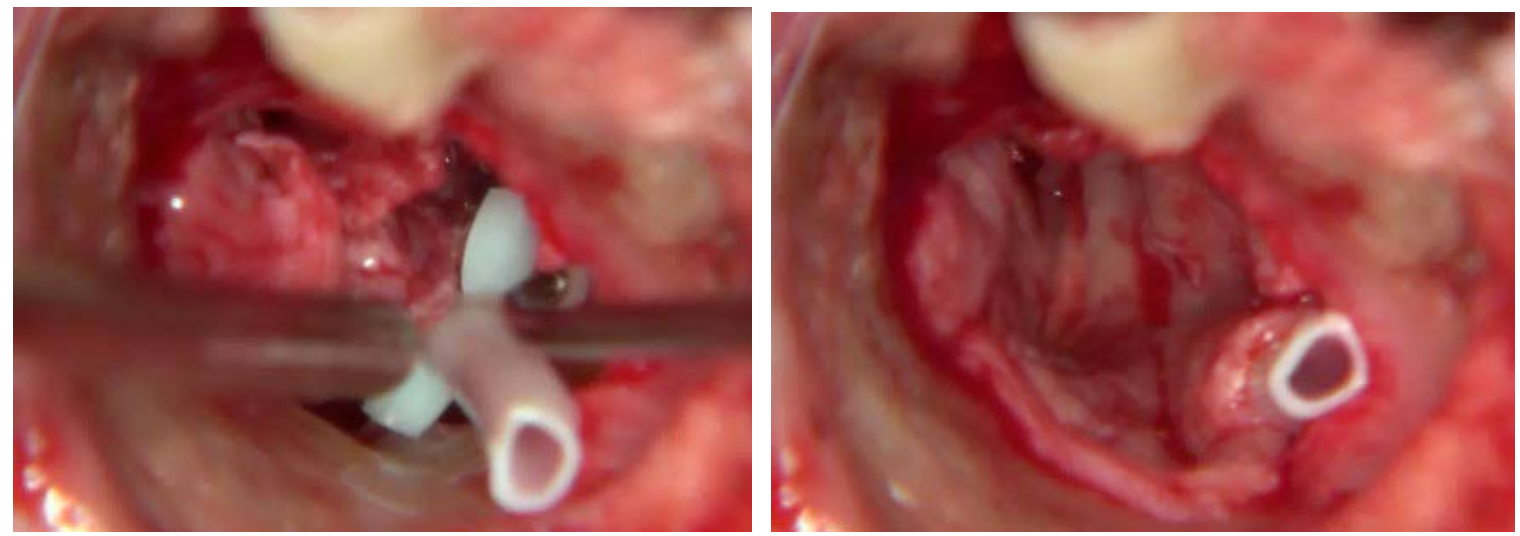

Fig. 4. Teflon VT in right external ear canal, under temporal fascia.

Ear dressing was removed in 1 month. At 3 months, there was not a complete epidermisation of the neotympanic membrane. The reduction of the air bone gap from $35 \mathrm{~dB}$ to $15 \mathrm{~dB}$ is noted. In the case of an inflation-deflation test, the $5^{\text {th }}$ grade of ET func- tion was noted. At 6 months, otomicroscopy shows complete epidermisation of a neotympanic membrane. In the audiometry study decreasing of the air bone gap to $10 \mathrm{~dB}$ was noted. In inflation-deflation test $3^{\text {rd }}$ grade of ET was detected (Fig. 5) 

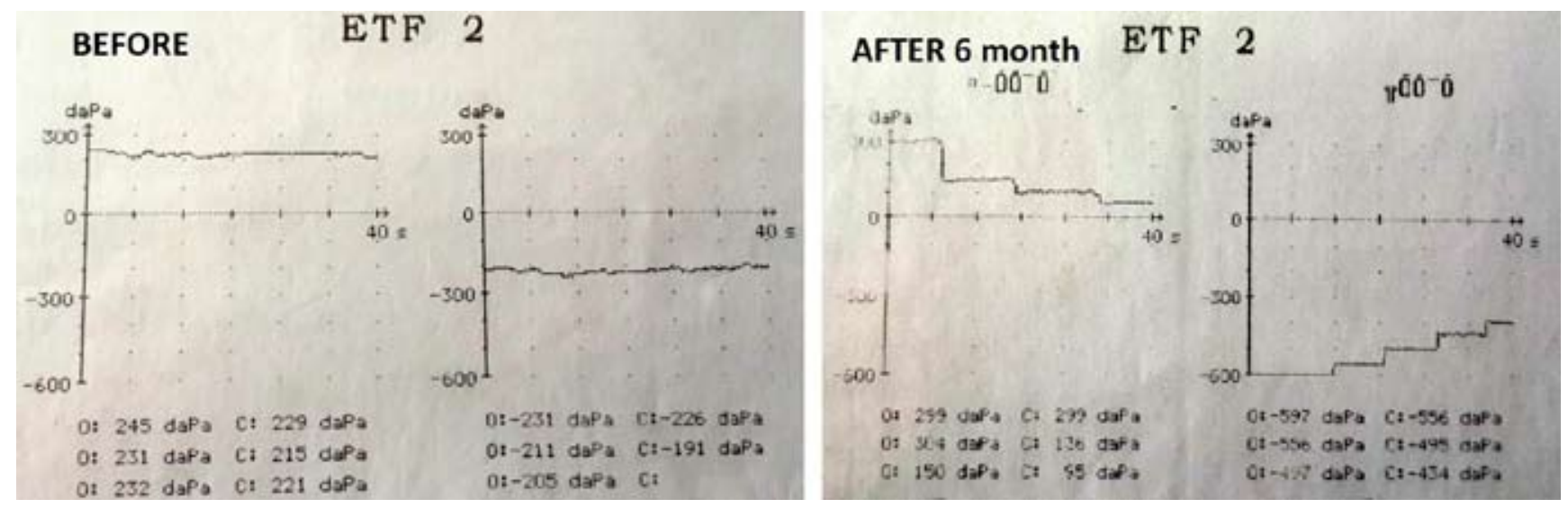

Fig. 5. Inflation-deflation test result before and after tympanoplasty with teflon VT.

Ventilation tube was removed. After 12 months neotympanic membrane is mobile, no dislocation of neotympanic membrane was observed. In the audiometry, decrease of the air bone gap to $5 \mathrm{~dB}$ was registered. Type A of tympanometry was noted.

\section{Conclusions}

1. Tympanoplasty in patients with chronic tubotympanic suppurative otitis media has positive affect on ET function.
2. Teflon and silicone VT during tympanoplasty leads to good healing of tympanic membrane in patients with 5th grade of ET function.

3. Inflation-deflation test is an objective method and should be used for ET function evaluation before tympanoplasty.

\section{References}

1. Boboshko MY, Lopotko AI. Eustachian tube. 2003. Russian.

2. Borysenko OM., Grynko I.I. Results of eustachian tube function study in patients with chronic otitis media. Zhurnal vushnyh, nosovyh i gorlovyh hvorob. 2014; 3-s: 212. Ukrainian.

3. Kruk MB. Definition of patency of the eustachian tube with otitis media in terms. Bulleten of otolaryngology. 1973; 5: 48-53. Russian.

4. Kruk MM. Defining the functional status of eustachian tube in purulent otitis media. Zhurnal vushnyh, nosovyh i gorlovyh hvorob. 2011; 3: 134-135. Ukrainian.

5. Kruk MB, Kruk MM. About ventilation function of eustachian tube. Zhurnal vushnyh, nosovyh i gorlovyh hvorob. 2011; 3: 135. Ukrainian.

6. Kruk MB, MM Kruk. Ventilation function of eustachian tube and methods of determining in intact tympanic membrane. Zhurnal vushnyh, nosovyh i gorlovyh hvorob. 2015; 4: 62-77. Ukrainian.

7. Lebedev J. A., Shahov V.J. Eustachian tube evaluation in patients with with otitis media with effusion. Vestnik otolaryngology, 1997, № 3. C. $30-34$.

8. Puhalsky AA. Definition of Eustachian tube patency using hearing. Voprosi medizinskogo snabjenia aviatsii. 1939; T1: 52-55. Russian.

9. Serdiuk S.N. Clinical and experimental substantiation of the method transmastoid ventilation in the treatment of acute and chronic diseases of the middle ear. the Dissertation for a scientific degree - Donetsk. 2002.

10. Sushko YA, Bessonov VI. To the question about the frequency of eustachian tube disfunction in patients with chronic otitis and their consequences. Zhurnal vushnyh, nosovyh i gorlovyh hvorob. 1971; 4: 77-83. Russian.

11. Sushko YA Rudenko YA. About tympanoplasty prognosis in patients with severe dysfunction of the eustachian tube according to the aspiration method. Zhurnal vushnyh, nosovyh i gorlovyh hvorob. 1976; 2: 59-61. Russian.

12. Ars B. Ars-Piret N. Middle ear pressure balance under normal conditions. Specific role of the middle ear structure. Acta Otorhinolaryngol. - 1994, № 48(4), P. 339-342

13. Elluru R. G., Dhanda R. Anterior subannular T-tube for prolonged middle ear ventilation during tympanoplasty: evaluation of efficacy and complications. Otol Neurotol., 2001, №22, P. 761-765.

14. Miller G. F. Eustachian tubal function in normal and diseased ears. Arch Otolaryngol - 1965, Vol. 81., P. 41-48. 